\title{
Apical dominance and the importance of clonal integration to apical growth in the seagrass Syringodium filiforme
}

\author{
Arthur C. Schwarzschild ${ }^{1, *}$, Joseph C. Zieman ${ }^{2}$ \\ ${ }^{1}$ Department of Environmental Sciences, University of Virginia, Anheuser-Busch Coastal Research Center, PO Box 55, \\ Cheriton, Virginia 23316, USA \\ ${ }^{2}$ Department of Environmental Sciences, University of Virginia, PO Box 400123, Charlottesville, Virginia 22904, USA
}

\begin{abstract}
The existence of apical dominance and the importance of clonal integration to apical growth in the seagrass Syringodium filiforme were examined using field and mesocosm experiments. In the field, apical dominance was observed with proliferative branching resulting from the removal of rhizome apical meristems (RAMs). Rhizome internode length and branching increased when plants grew from a dense meadow into a bare patch, providing further evidence for the existence of apical dominance in $S$. filiforme. The results of the experiments indicated that growth of the RAM is dependent on the translocation of resources from older ramets. Removing 3 shoots from a rhizome runner lead to a significant reduction in the growth of the RAM, and removing 6 shoots had a greater effect. Apical growth was more significantly affected by cutting the rhizome, with the lowest growth observed in clonal fragments comprised of a RAM and the 4 youngest ramets. We conclude that clonal integration is an important factor regulating the growth form and productivity of $S$. filiforme. These results have implications for damage assessment and restoration projects, and indicate that future studies of meadow structure and plant production should consider RAM health and branch formation along with individual ramet growth.
\end{abstract}

KEY WORDS: Apical dominance $\cdot$ Clonal integration $\cdot$ Syringodium filiforme $\cdot$ Seagrass

\section{INTRODUCTION}

Seagrasses are clonal plants (Fig. 1) that rely on asexual reproduction via growth and branching of rhizome apical meristems (RAMs) along with the dispersal and recruitment of vegetative fragments for population maintenance and proliferation (Tomlinson 1974, Dawes 1981, Hemminga \& Duarte 2000). The ability of seagrass meadows to recover from disturbance and expand vegetatively into adjacent areas is determined by (1) the growth rate of the primary RAM; (2) the frequency of branch formation, branching angle and the growth rate of branches; and (3) the production, transport and recruitment of clonal fragments (Tomlinson 1974, Marbà \& Duarte 1998, Hemminga \& Duarte 2000, Kenworthy et al. 2002). Rhizome RAMs are phys- iologically active tissues that require a supply of soluble carbohydrates and nutrients to support cell division, the formation of new plant parts and growth (Tomlinson 1974, Duarte \& Sand-Jensen 1996, Terrados et al. 1997b). Additionally, young ramets (short shoots and their associated roots and rhizome sections) that have not yet reached a mature height in the leaf canopy, where they can gain sufficient light for net photosynthesis, also require some degree of support from older parts of the clone. As a result, the young, growing portion of a seagrass clone (which we refer to as a rhizome runner, and which is comprised of a RAM, a section of rhizome and attached ramets [Fig. 1]) may act as a physiological sink, drawing nutrients and carbohydrates from older portions of the clone (Libes \& Boudouresque 1987, Tomasko \& Dawes 1989, Duarte \& 




Fig. 1. Syringodium filiforme. (A) Location of the rhizome RAM. (B) Box indicates Number 4 (4th youngest) ramet (including short shoot) on the rhizome runner

Sand-Jensen 1996, Hemminga \& Duarte 2000, Marbà et al. 2002). Therefore, information concerning apical dominance and clonal integration, 2 physiological processes that control RAM branching and growth, are essential to understanding formation, maintenance and expansion of seagrass meadows.

Apical dominance is defined as the control of ramet or lateral branch formation exerted by the RAM, and is typically thought to function through the release of hormones translocated from the RAM through the rhizome to suppress branch formation at other growth sites (Little \& Jones 1980, Cline 1991, Salisbury \& Ross 1992, Callaghan et al. 1997, Watson et al. 1997). This hormonal signal is diluted with distance from the RAM and as a result, branching sites removed from the RAM may be released from apical dominance. Destruction of the RAM can also result in loss of the hormonal signal and release from branch suppression. Since monitoring and measuring hormone production is technically difficult and expensive, growth response to physical manipulations is commonly used to infer hormonal activity (Salisbury \& Ross 1992, Terrados et al. 1997a, Watson et al. 1997).

Environmental conditions can effect the expression of apical dominance. Increased light availability and alterations in the red-to-far-red light ratio associated with canopy disturbances and gap formation have been reported to release plants from apical dominance, resulting in proliferative branching patterns (Cline 1991, Salisbury \& Ross 1992, van der Hoeven \& During 1997). Plants growing into localized zones of higher nutrient availability or altered sediment characteristics may also exhibit a release from apical dominance and increased branching (Cline 1991, Duarte \& Sand-Jenson 1996, van Tussenbroek et al. 2000).

Van Tussenbroek et al. (2000) reported evidence for apical dominance in the seagrass Thalassia testudinum and documented the existence of dormant meristems that could be activated by adding nutrients, thereby significantly increasing branching rates. Terrados et al. (1997a) demonstrated that apical dominance was exhibited in the seagrass Cymodocea nodosa and showed that the probability of branching for the ramet closest to the RAM increased significantly if the meristem was removed. Their results also indicate that total plant production decreased with removal of the RAM, most likely due to wound response and the shunting of energy from normal growth to the production of new RAMs. In contrast, Cabaço et al. (2005) determined that apical dominance was not exhibited in the seagrass Zostera noltii.

Clonal integration, defined as the physiological linkage between individual ramets in a clone, involves the sharing of resources such as nutrients and carbohydrates, and requires the maintenance of a physical connection between plant modules (Little \& Jones 1980, Salisbury \& Ross 1992). Using manipulative field experiments, Terrados et al. (1997b) reported that both RAM growth and new ramet formation in Cymodocea nodosa are dependent on the translocation of resources from older ramets. By severing or leaving intact the rhizome connections between shaded and unshaded ramets, and measuring soluble carbohydrate levels, Tomasko \& Dawes (1989) detected physiological integration in Thalassia testudinum. In a subsequent study of transplanted T. testudinum clonal fragments, Tomasko et al. (1991) observed higher mortality and lower growth in smaller fragments compared to larger fragments and intact runners. Evidence for clonal integration has been reported for Syringodium filiforme, as shaded plants connected to unshaded plants maintained higher concentrations of soluble carbohydrates in the leaves and rhizomes than did shaded, isolated plants (Rey \& Stephens 1996). Longdistance translocation of nutrients and carbohydrates has also been observed in the tropical seagrasses $C$. serrulata, Halophila stipulacea, Halodule uninervis, Thalasodendron ciliatum and Thalassia hemprichii, and in the temperate seagrasses C. nodosa, Posidonia oceanica, and Zostera noltii (Libes \& Boudouresque 1987, Marbà et al. 2002).

Many seagrass species grow in shallow water and are subject to both natural and anthropogenic disturbances, including grazing by sea turtles, manatees, rays and sea urchins, excessive water motion and erosion events associated with storms, dock construction, 
dredging, commercial fishing using dragged gear, and propeller dredging. These disturbances are capable of removing shoots from rhizome sections and cutting rhizomes, thereby severing the connection of ramets with the RAM (Zieman 1982, Sargent et al. 1995, Fonseca et al. 1998, Hemminga \& Duarte 2000, Lefebvre et al. 2000, Kenworthy et al. 2002, Cabaço et al. 2005). The degree of apical dominance and physiological integration exhibited by seagrass species should play a large role in determining how species respond to these disturbances. This paper provides experimental evidence for the existence of apical dominance and the importance of clonal integration to apical growth in the seagrass Syringodium filiforme, and discusses the implications apical branching and physiological integration patterns have on population maintenance, recovery from disturbance events, and exploitation of new environments.

\section{MATERIALS AND METHODS}

The existence of apical dominance and the importance of clonal integration to apical growth in Syringodium filiforme were determined using 2 field and 2 mesocosm experiments, which manipulated RAMs, rhizome length and the number of shoots on rhizome runners. For all experiments the plant material was either sampled or collected along the edges of unvegetated patches in a nearly monospecific $S$. filiforme meadow adjacent to Sprigger Bank $\left(24^{\circ} 54.73^{\prime} \mathrm{N}, 80^{\circ} 56.19^{\prime} \mathrm{W}\right)$ on the western border of Florida Bay, Florida, USA. The mesocosm experiments were conducted in Sunset Cove $\left(25^{\circ} 04.46^{\prime} \mathrm{N}\right.$, $80^{\circ} 27.36^{\prime} \mathrm{W}$ ) in the northeastern portion of Florida Bay. Additional evidence for apical dominance was derived by analyzing morphological differences observed in plants growing from a dense seagrass meadow into an unvegetated area, also in the vicinity of Sprigger Bank.

Field experiments. To initiate the field experiments, several adjacent, soft-bottom unvegetated patches with a minimum diameter of $2 \mathrm{~m}$ were located and identified. We selected 120 Syringodium filiforme rhizome runners growing into the unvegetated patches from the bordering meadow and randomly assigned them to one of 6 treatment groups, with 20 runners in each group distributed haphazardly along the edges of the unvegetated patches. Rhizome runners were tagged with numbered, color-coded plastic cable ties placed around the rhizome between the first and second ramet behind the RAM (Fig. 2). The 6 experimental treatment groups consisted of (1) Control = tagging only, with no additional manipulation of rhizome or ramets; (2) Apical cut = tagged runners with the rhizome RAM removed; (3) 3-Cropped = tagged runners with the third, fourth and fifth shoots removed by cutting the vertical stems immediately above the insertion points on the rhizome; (4) 6-Cropped = tagged runners with the third through eighth shoots removed; (5) 7 Cut $=$ tagged runners with the rhizome cut behind the seventh ramet; and (6) 4-Cut = tagged runners with the rhizome cut behind the fourth ramet. After tagging and manipulating each runner, the distance between the RAM and the first ramet was measured and recorded. The presence, position and length of any branches within 10 ramets of the RAM were also recorded. Runners were allowed to grow for 5 to $6 \mathrm{wk}$ before being harvested for analysis.

In 1999, runners from the apical cut treatment were harvested by following the runner as far back behind the tag as possible, before cutting the rhizome and extracting it from the sediments. Runners from the other treatment groups were harvested by cutting the rhizomes one ramet behind the tag and collecting the



Fig. 2. Treatments used in field experiments. See 'Materials and methods, Field experiments' for further details 
new growth. In 2000, runners were harvested collecting as much material behind the tag as possible for all treatment groups. The number of new ramets produced by runners during the growth period was determined by counting the ramets or rhizome internode scars in front of the tags and subtracting one, since the tags had been placed behind the first ramet. Rhizome growth was determined by measuring the length of the rhizome in front of the tag and subtracting the distance between the RAM and the first ramet that had been recorded at the start of the experiment. The number, position and lengths of branches were recorded and compared to the data collected at the start of the experiment to determine branch formation and growth. New biomass produced by the runners during the experiments was rinsed to remove adhering carbonate material, dried at $60^{\circ} \mathrm{C}$ and weighed.

Evidence for apical dominance in Syringodium filiforme was determined by comparing the numbers and positions, relative to the RAM at the start of the experiment, of branches and new rhizome RAMs formed on runners from the apical-removed and control treatments. The importance of clonal integration for apical growth was determined by comparing the numbers of ramets produced, rhizome growth and total new biomass of control and manipulated runners. Data were tested for normality and homogeneity of variance prior to using 1-way ANOVA followed by Student-NeumanKeuls test (SNK) with an $\alpha=0.05$ to test differences among treatments.

Field monitoring. During the summer of 2001, a field survey was conducted to collect further evidence of apical dominance in Syringodium filiforme. Rhizome runners growing into unvegetated areas were identified and carefully excavated from the apical end, back to the edge of the seagrass meadow. As the runners were excavated, a plastic cable tie was placed around the rhizome to mark the point where the runner grew out of the meadow and into the unvegetated area. The number of rhizome internodes on the primary growth axis in front of the cable tie was counted and the runner was harvested by cutting it at a point an equal number of internodes back into the meadow (behind the tie). On a calm summer day with clear skies a 4- $\pi$ quantum photosynthetically active radiation (PAR) sensor was used to collect 5 replicate light measurements at each site near midday to determine maximum light levels at canopy height in the meadow and unvegetated area.

In the lab, the number of branches produced by runners in the meadow and unvegetated area were counted, and the lengths of rhizome internodes on the primary growth axis were recorded for internodes in front of and behind the cable tie. The number of branches produced by runners in the meadow and unvegetated area, and the lengths of rhizome internodes generated inside the meadow and in the unvegetated area were compared using $t$-tests $(\alpha=0.05)$.

Mesocosm experiments. To further examine the potential importance of clonal integration to apical growth, mesocosm experiments were conducted in 2002. Mesocosms used for the experiments consisted of plastic tubs $(80 \times 50 \times 20 \mathrm{~cm})$ positioned in the center of a hard-bottom, bare area in Sunset Cove, Florida Bay, anchored in place with rebar poles and filled with carbonate screening sand (Florida Rock and Sand). Mean grain size of the screening sand was coarser than that of the sediments at the donor site where the plants originated, but was similar to sediments collected from Syringodium filiforme patches growing on Sprigger Bank, Red Bay Bank and the Florida Keys Reef Tract (Schwarzschild 2004), indicating that it was suitable to anchor the plants and support growth. Water depth, temperature and light levels at the mesocosm site were similar to those observed around Sprigger Bank during the experimental period (Schwarzschild 2004).

Prior to the initiation of each mesocosm experiment, rhizome runners with intact rhizome RAMs and a minimum of 10 healthy, intact, consecutive ramets were harvested from soft-bottom, bare areas in the vicinity of Sprigger Bank and planted in the mesocosms. Fifteen runners were planted per mesocosm and allowed to acclimate for a minimum of $10 \mathrm{~d}$. The first mesocosm experiment was initiated on June 6, 2000, and used 5 mesocosm tubs. The 9 most robust runners in each tub were selected for use in the experiment and the 6 remaining runners were removed. Three runners from each tub were randomly assigned to one of 3 treatment groups, for a total of 15 replicates in each group. The 3 treatment groups consisted of a runner with a RAM and (1) the 10 consecutive youngest ramets, (2) the 7 consecutive youngest ramets, and (3) the 4 consecutive youngest ramets (Fig. 3). Once a runner had been assigned to a treatment group it was tagged with a numbered, color-coded plastic cable tie between the first and second ramet. The distance between the RAM and first ramet was measured and recorded, and the runner was trimmed to the appropriate size. Runners were allowed to grow for $20 \mathrm{~d}$, after which they were harvested, transported to the lab and analyzed to determine new growth following the procedures used in the field experiments. Data were tested for normality and homogeneity of variance prior to using 1-way ANOVA followed by SNK with an $\alpha=0.05$ to test differences among treatments.

A second mesocosm experiment initiated on September 30, 2002, utilized 6 mesocosms and 3 experimental treatments, which consisted of a rhizome runner with an intact RAM and (1) 7 consecutive ram- 
TREATMENT

10 ramets 0
A

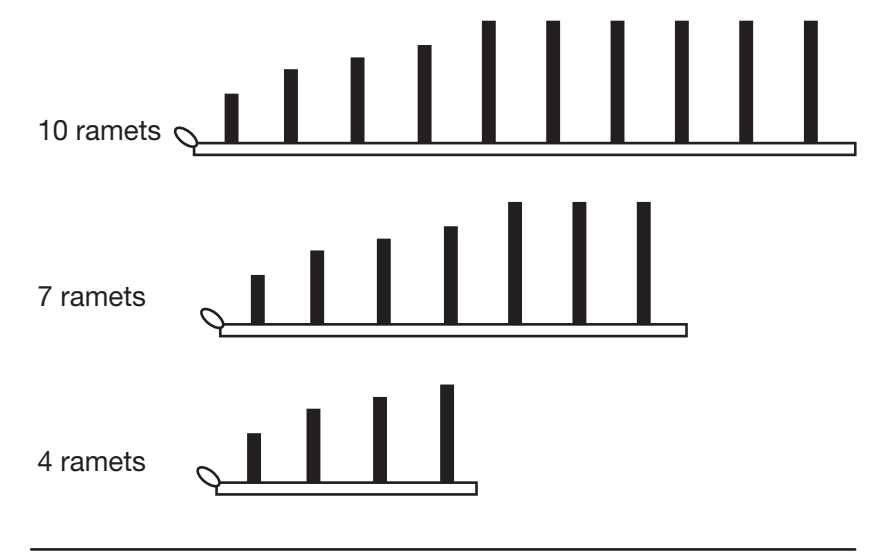

7 ramets

3 ramets with extra rhizome

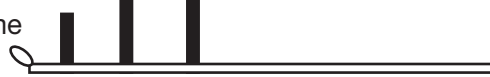

3 ramets

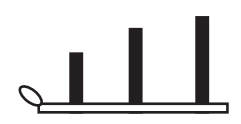

Fig. 3. Treatments used in mesocosm experiments. (A) First and (B) second mesocosm experiment ets, (2) a rhizome section of 7 ramets from which the last (oldest) 4 shoots had been removed, and (3) the 3 consecutive youngest ramets (Fig. 3). Runners were randomly assigned to treatments such that each tub contained 3 runners from 2 treatment groups and 4 runners from 1 treatment group providing 20 replicate runners per treatment group. Runners were manipulated and initial measurements were made as described above. Following a 20 d growth period the runners were harvested and transported to the lab for analysis as described above.

\section{RESULTS}

Of the 120 runners tagged at the start of the 1999 field experiment, only 50 were successfully located and recovered in measurable condition (Table 1). As a result of vandalism, runner recovery at the end of the 2000 field experiment was lower than in 1999, and only 32 runners were successfully harvested. This low recovery success reduced the sample sizes and affected the data analysis (Table 1).

\section{Evidence for apical dominance}

\section{Field experiments}

Analysis of runners from the 1999 experiment revealed a substantial increase in branching of the apical cut treatment compared to runners from the control

Table 1. Syringodium filiforme. Effects of rhizome cutting and shoot cropping on branching and growth of rhizome runners during field experiments (mean \pm SE). Rz: rhizome; nd: no data; p given when statistical analyses were performed. Data are no., unless otherwise indicated. Runners: no. tagged and recovered. \% Branch at P1: percentage of runners that produced a branch at the youngest ramet relative to the position of the RAM at the start of the experiment

\begin{tabular}{|c|c|c|c|c|c|c|}
\hline & Runners & New branches & Branch at P1 (\%) & New ramets & Rz growth (cm) & Biomass (g DW) \\
\hline \multicolumn{7}{|l|}{1999} \\
\hline Control & 5 & 0 & 0 & $8.6 \pm 0.4$ & $29.3 \pm 2.3$ & 0.320 .03 \\
\hline Apical cut & 11 & $2.7 \pm 0.3$ & 100 & nd & nd & nd \\
\hline 3-Cropped & 8 & 0 & 0 & $7.4 \pm 0.3$ & $24.4 \pm 1.3$ & $0.22 \pm 0.02$ \\
\hline 6-Cropped & 10 & 0 & 0 & $6.8 \pm 0.4$ & $21.2 \pm 2.1$ & $0.24 \pm 0.03$ \\
\hline 7-Cut & 7 & 0 & 0 & $5.6 \pm 0.2$ & $15.6 \pm 1.1$ & $0.13 \pm 0.01$ \\
\hline 4-Cut & 9 & 0 & 0 & $2.7 \pm 0.2$ & $4.3 \pm 0.7$ & $0.05 \pm 0.00$ \\
\hline $\mathrm{p}$ & & & & 0.000 & 0.000 & 0.000 \\
\hline \multicolumn{7}{|l|}{2000} \\
\hline Control & 8 & $1.1 \pm 0.5$ & 0 & $6.6 \pm 0.9$ & $26.2 \pm 4.7$ & \\
\hline Apical cut & 8 & $3.6 \pm 0.5$ & 100 & nd & nd & \\
\hline 3-Cropped & 5 & nd & 0 & $3.5 \pm 0.6$ & $7.0 \pm 1.7$ & \\
\hline 6-Cropped & 7 & nd & 0 & $5.8 \pm 0.5$ & $17.8 \pm 2.4$ & \\
\hline 7-Cut & 0 & nd & nd & nd & nd & \\
\hline 4-Cut & 4 & nd & 0 & $1.0 \pm 0.0$ & $3.6 \pm 0.8$ & \\
\hline $\mathrm{p}$ & & & & 0.001 & 0.001 & \\
\hline
\end{tabular}


and other experimental treatment groups (Table 1). All of the runners from the apical cut treatment produced at least one branch during the experimental growth period. The majority of the runners from this treatment group produced multiple branches, with 2 runners producing 4 new branches, resulting in a mean of 2.7 new branches produced per runner. All but 1 of the runners in the apical cut treatment produced a branch from the ramet in front of the tag, which was the youngest ramet and was located directly behind the RAM at the start of the experiment. The youngest ramet was missing from the 1 runner that did not generate a branch at this position. Additional branches tended to be produced by the next youngest ramet; however, 1 runner generated a branch 6 ramets behind the position of the RAM at the start of the experiment. In contrast, no branches were formed at the ramet in front of the tag, or at any other position along the new growth of runners from the control or other treatment groups during the experimental growth period. Since runners from these groups were only harvested from one ramet behind the tag forward to the end of the new growth, there was no way to determine if they produced branches at older ramet positions during the growth period.

The collection of both old and new growth from the apical cut and control treatment runners successfully harvested in the 2000 experiment allowed for a more detailed analysis and comparison of branch formation (Fig. 4). As in the 1999 experiment, all of the runners in the apical cut treatment produced new branches during the experimental growth period. In all cases, a branch was formed by the youngest ramet on each runner in this treatment group, with 1 runner producing 3 branches at this location. All but 1 of the runners also branched at the second youngest ramet, with 1 of the runners producing 2 branches at this location. On several runners, branching was also observed further back, with 1 branch formed 8 ramets behind the position of the RAM at the start of the experiment. In comparison, only $50 \%$ of the control runners formed branches, and none of these branches were generated at the ramet in front of the tag. Instead, branches were formed further back on the runner, away from the RAM.

\section{Field survey}

Due to the difficulty of extracting intact runners from the dense rhizome matrix of the $S_{y}$ ringodium filiforme meadow, only 9 long runners were successfully harvested. However, even with this limited sample size, we detected a significant change in growth form as runners grew from the meadow into the unvegetated
Table 2. Syringodium filiforme. Light levels $(\mathrm{n}=5)$ and rhizome morphology in 9 plants observed growing from a dense meadow into an unvegetated area during a field survey in summer 2001(mean \pm SE)

\begin{tabular}{|lccc|}
\hline & $\begin{array}{c}\text { Light levels } \\
\left(\mu \mathrm{E} \mathrm{m}^{-2} \mathrm{~s}^{-1}\right)\end{array}$ & $\begin{array}{c}\text { Internode } \\
\text { length }(\mathrm{cm})\end{array}$ & $\begin{array}{c}\text { Branches } \\
\left(\text { no. runner }^{-1}\right)\end{array}$ \\
\hline Meadow & $531 \pm 25.0$ & $3.6 \pm 0.1$ & $0.2 \pm 0.2$ \\
Unvegetated area & $847 \pm 15.0$ & $4.0 \pm 0.1$ & $3.6 \pm 1.0$ \\
$\mathrm{p}$ & 0.000 & 0.001 & 0.010 \\
\hline
\end{tabular}

area (Table 2). Both rhizome internode length and branching increased significantly as runners grew into the unvegetated area. Mean rhizome internode length in the unvegetated area was $4.0 \mathrm{~cm}$, compared to $3.6 \mathrm{~cm}$ in the meadow. All but 1 of the runners branched in the unvegetated area, with the majority producing multiple branches and one runner having 10 branches in the unvegetated area. In contrast, only 1 of the runners had branched inside the meadow, producing 2 branches. Light availability was significantly higher in the unvegetated area than in the meadow canopy (Table 2).

\section{Evidence for clonal integration}

Field experiments

Apical growth in the 1999 field experiment was greatest in the control group, with a mean of 8.6 new ramets produced and a rhizome growth of $29.3 \mathrm{~cm}$ during the $35 \mathrm{~d}$ experiment (Fig. 5). Cropping shoots from runners caused a significant reduction in ramet formation, with the 3-Cropped and 6-Cropped treatments forming 7.4 and 6.8 new ramets respectively. Rhizome growth was also reduced in the cropped treatments, significantly so in the case of the 6-Cropped runners, which had a mean growth of $21.2 \mathrm{~cm}$. Cutting the rhizome caused a greater reduction in growth than did

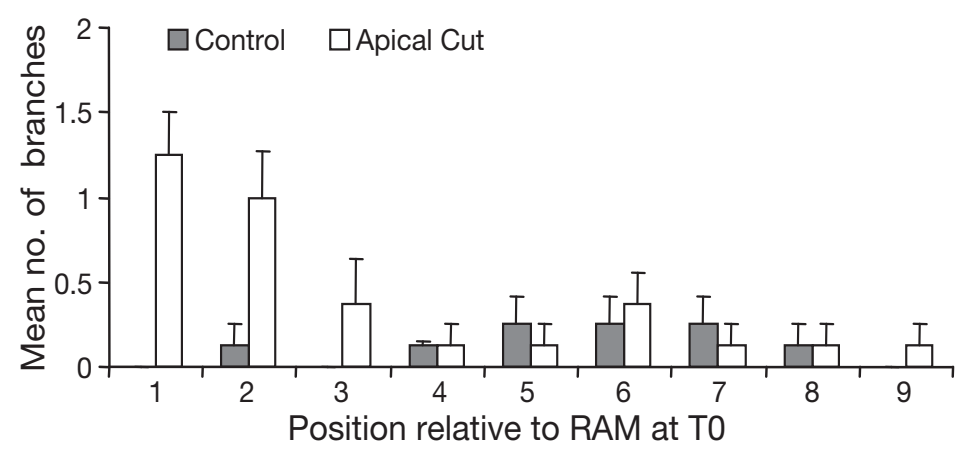

Fig. 4. Syringodium filiforme. No. of branches (mean $+\mathrm{SE})$ produced at each location along the rhizome relative to the position of the rhizome apical meristem (RAM) at the start of summer 2000 field experiment conducted at Sprigger Bank 
cropping shoots from the rhizome, and smaller fragments (4 ramets) had lower growth than larger fragments $(7$ ramets). The mean number of new ramets produced by runners from the 7-Cut treatment was 5.6, significantly lower than the control and cropped treatments, but significantly higher than the mean of 2.7 new ramets produced by runners in the 4 -Cut treatment. Similarly, the mean rhizome growth of $15.6 \mathrm{~cm}$ produced by runners in the 7 -Cut treatment was significantly lower than that observed in the control and cropped treatments, but significantly higher than the mean growth of $4.3 \mathrm{~cm}$ determined for runners from the 4-Cut treatment. Total biomass production followed a similar trend, with the control runners generating the most new biomass, and the 4-Cut runners generating the least.

Low recovery success of runners from the 2000 experiment reduced the quality of the data generated. However, the limited data set showed a similar trend to that observed in the 1999 experiment, with the control runners having the highest growth. Ramet formation and rhizome growth were lower in both the 3-Cropped and 6-Cropped treatment groups, and the 4 -Cut treatment showed the lowest growth (Fig. 6).
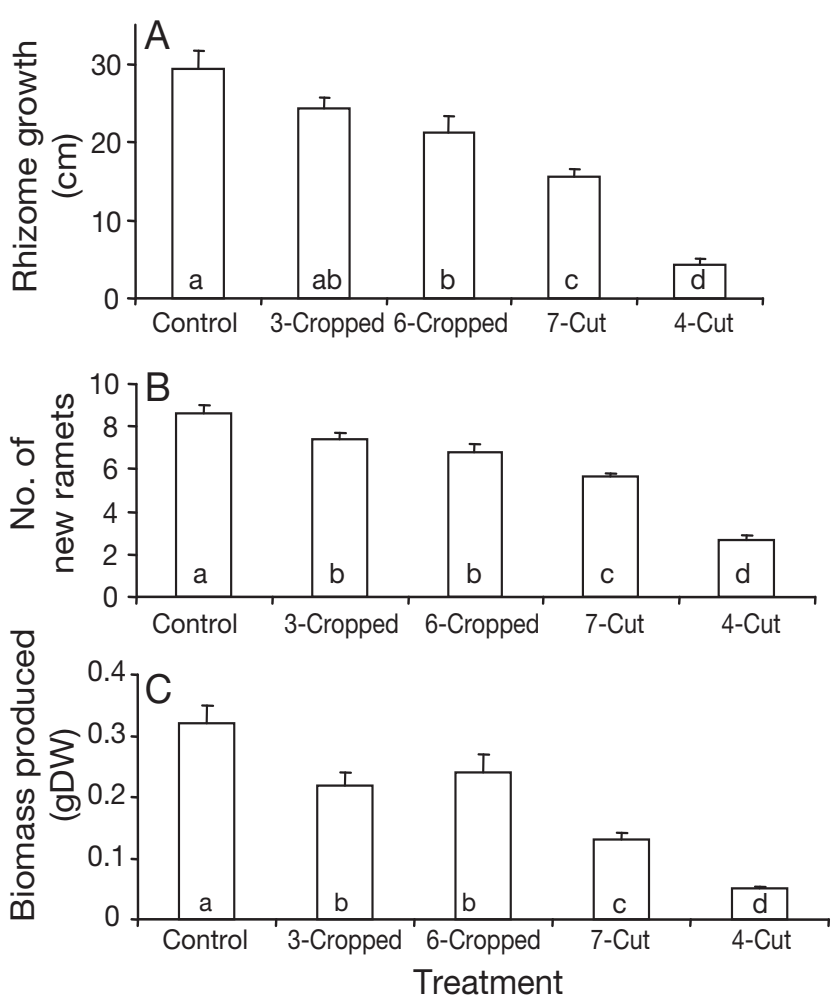

Fig. 5. Syringodium filiforme. (A) Rhizome growth, (B) ramet formation and (C) biomass production measured during summer 1999 clonal integration field experiment conducted at Sprigger Bank. Data are mean + SE. Different letters indicate significant differences among treatments

\section{Mesocosm experiments}

Growth rates in the mesocosms were reduced compared to those measured in the field, but the results of the mesocosm experiments supported the results of the field experiments. In the first mesocosm experiment, runners with 10 ramets grew the most, on average generating 3.2 new ramets and producing $7.9 \mathrm{~cm}$ of new rhizome during the $20 \mathrm{~d}$ experiment (Fig. 7). In comparison, runners with 7 and 4 ramets formed only 2.4 and 1.4 new ramets respectively, and produced only 6.5 and $2.7 \mathrm{~cm}$ of new rhizome respectively. The mean number of new ramets formed and the rhizome growth were significantly different among treatments.

Many of the clonal fragments used in the second mesocosm experiment did not survive to the end of the monitoring period, with the highest mortality observed in the smaller clonal fragments (Table 3). Only 7 of the cropped runners survived to the end of the experiment, and of these, only 3 retained a RAM. In the cut treatments, 6 runners survived, 5 of which retained a RAM. Of the 21 runners that survived the experiment retaining RAMs, 11 produced new growth, with 8 control runners, 1 cropped runner, and 3 cut runners generating new ramets and rhizome material. The low survival of runners from the cropped and cut treatments reduced the sample size available for growth analysis at the end of the experiment, so that an ANOVA could not be used to compare the variables of new ramet formation or rhizome growth. Instead, a chi-squared test was performed comparing fragment and RAM



Fig. 6. Syringodium filiforme. (A) Rhizome growth and (B) ramet formation during summer 2000 clonal integration field experiment. Data are mean + SE. Different letters indicate significant differences among treatments 


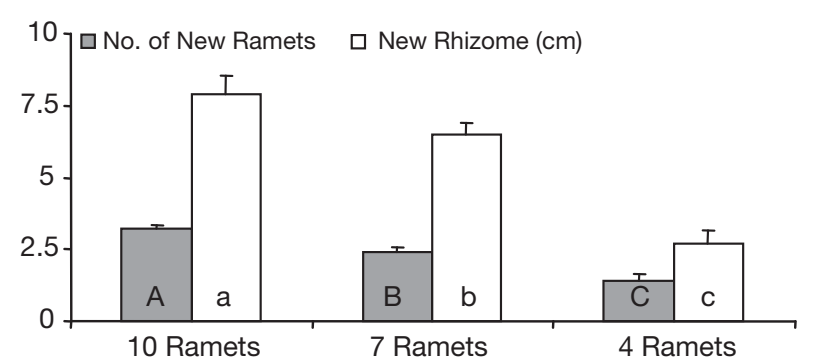

Fig. 7. Syringodium filiforme. Effect of fragment size on apical growth and ramet formation during the first mesocosm experiment conducted in Sunset Cove. Data are mean + SE. Different letters indicate significant differences among treatments

survival. Runner and RAM survival were significantly higher for the control runners than for either the cropped or cut treatments, which were not significantly different from each other.

\section{DISCUSSION}

The existence of apical dominance in the seagrass Syringodium filiforme was shown by the increase in branching observed following experimental removal of RAMs. Further evidence of apical dominance can be inferred from the locations of branches produced on manipulated and control runners. Removal of RAMs from rhizome runners resulted in increased branch formation. Mean branch formation on manipulated runners was more than double that of control runners. In all cases, RAM removal caused the youngest remaining ramet (the ramet in front of the tag) to branch, generating a new horizontal growth axis. Branches were also formed at the second-to-youngest ramet on the majority of manipulated runners and several runners produced additional branches from older ramets. In comparison, none of the control runners branched at the ramet in front of the tag and no branches were formed along the length of new rhizomes that grew during the experiment. The few branches that were produced on control runners were located well behind

Table 3. Syringodium filiforme. Survival $\left(\chi^{2}\right.$ test used to compare clonal fragments and RAMs), ramet production and rhizome growth from the 2nd mesocosm experiment (mean $\pm \mathrm{SE}$ ). Low survival of cropped and cut treatments precluded the possibility for statistical comparisons of runner growth. Rz: rhizome

\begin{tabular}{|lcccc|}
\hline & $\begin{array}{c}\text { Fragment } \\
\text { survival }\end{array}$ & $\begin{array}{c}\text { Apical } \\
\text { survival }\end{array}$ & $\begin{array}{c}\text { New } \\
\text { ramets }\end{array}$ & $\begin{array}{c}\text { New rhizome } \\
(\mathrm{cm})\end{array}$ \\
\hline Control & 18 & 13 & $0.8 \pm 0.2$ & $0.7 \pm 0.2$ \\
Cropped & 7 & 3 & $0.3 \pm 0.3$ & $0.4 \pm 0.4$ \\
Rz cut & 6 & 5 & $0.6 \pm 0.2$ & $0.6 \pm 0.3$ \\
$\chi^{2} \mathrm{p}$ & 0.001 & 0.01 & & \\
\hline
\end{tabular}

the RAM, with only 1 branch formed at the ramet located 2 positions behind the RAM at the start of the experiment. These results suggest that as ramets age and the RAM grows further away from them, they may be released from apical dominance and branch suppression. Therefore, on runners with healthy RAMs, branches will tend to be found on older ramets, away from the RAM. In comparison, runners with damaged RAMs may branch profusely at the youngest ramets.

In their study of apical dominance in the seagrass Cymodocea nodosa, Terrados et al. (1997a) noted that removal of the RAM resulted in a change in growth form and branch formation at the youngest ramet. They did not, however, observe a significant increase in branching at other locations along the rhizome. The branching response of $C$. nodosa resulted in the replacement of lost RAMs and maintenance of the whole plant growth form. Tomlinson (1974) termed this branching pattern, 'regenerative branching' and suggested that it would aid a seagrass meadow in withstanding events that result in the loss of RAMs. Regenerative branching would also aid in re-colonization of disturbance areas where RAMs may be lost due to physical disturbances or sub-optimal growth conditions. In contrast, Syringodium filiforme exhibited what Tomlinson (1974) described as 'proliferative branching,' responding to RAM removal by (1) producing multiple branches generating several new growth axes; and (2) increasing the number of RAMs, thereby significantly altering whole plant growth patterns. The formation of multiple new growth axes should make species that exhibit proliferative branching more resistant to disturbance events than species characterized by regenerative branching. Additionally, proliferative branching should speed re-colonization of proximal disturbance areas and confer a competitive advantage to species growing in disturbance-prone habitats.

Further evidence of proliferative branching in $\mathrm{Sy}$ ringodium filiforme was obtained from the 2001 field survey. Runners growing from a dense meadow into an adjacent unvegetated area underwent a significant change in morphology, producing longer rhizome internodes and multiple branches in the unvegetated area. This change in morphology could be a result of differences in the light field, nutrient availability, sediment characteristics, energy regime or space occupation (Cline 1991, Duarte \& Sand-Jensen 1996, van Tussenbroek et al. 2000, Marbà \& Duarte 2003). Plants growing in the dense meadow experience selfshading and reduced light availability compared to plants growing in the unvegetated area (Table 3). The leaf canopy of seagrass beds can baffle 
water currents, reducing physical energy and potentially altering sediment characteristics and nutrient availability compared to unvegetated areas (Fonseca et al. 1982, Fonseca \& Fisher 1986). While the results of the field survey cannot determine which environmental variable is responsible for the alteration in plant growth form, it is clear that apical dominance was released when runners grew from the meadow into the unvegetated area. Plants that respond to gaps in the vegetation canopy in this way have been described as using a 'guerilla' strategy to exploit localized areas of resource abundance by rapidly expanding and occupying the space before other, slower-growing species (Lovett Doust 1981, Lovett Doust 1987). In contrast, the 'phalanx' growth strategy involves the slow and steady expansion of a species over an area with constant growth rates through regions of high and low resource availability (Lovett Doust 1981, Lovett Doust 1987, De Kroon \& Schieving 1991). Increased rhizome internode length and branching observed in guerilla species may be an evolutionary response to disturbance-prone environments (De Kroon \& Schieving 1991, Grime 1994). The ability of $S$. filiforme to alter growth form in this way may explain why it can become the dominant species in disturbance environments, enabling it to out-compete Thalassia testudinum, which is typically considered the climax species (e.g. Williams 1987).

The results of the clonal integration field experiments indicate that both apical growth and new ramet formation in Syringodium filiforme are dependent on resources translocated from older portions of the clone. The removal of as few as 3 shoots from a runner reduced the growth potential of the RAM, while cropping 6 shoots had a significantly greater effect. Cutting the rhizome had a more deleterious effect than did the removal of shoots from a clone. Growth of clonal fragments comprised of a runner with a RAM and the 7 youngest consecutive ramets was significantly lower than un-manipulated control runners or those that had been manipulated by cropping shoots. Smaller clonal fragments, runners with a RAM and only 4 ramets, had an even lower growth potential. The results of the field studies were confirmed by the first mesocosm experiment, in which larger clonal fragments grew faster than smaller fragments. The fact that cropping the third through eighth shoots from a runner did not reduce growth as much as cutting the rhizome behind the seventh ramet indicates that RAM growth is supported by resources translocated from ramets located at least 9 ramets away from the RAM. Since the mean distance between ramets in this area is $4.1 \mathrm{~cm}$ (Schwarzschild 2004), these results indicate that RAMs are supplemented by resources translocated from over $35 \mathrm{~cm}$ away. The results of the field experiments also suggest that RAMs require material produced and transported from older ramets, and not simply the remobilization of resources stored in the rhizome tissues. This conclusion is further supported by the results of the second mesocosm study, in which clonal fragments comprised of a RAM and 7 healthy ramets had a higher survival and growth potential than fragments comprised of a RAM and a similar length of rhizome, but with only 3 attached shoots. The high mortality and limited growth of the surviving cropped runners indicate that resources stored in the rhizome were insufficient to support growth of the RAM and young ramets. Additional evidence of long-distance transport of resources in $S$. filiforme reported by Rey \& Stephens (1996) shows the effects of shading and rhizome isolation on the soluble carbohydrate levels of $S$. filiforme leaves and rhizomes. They reported that isolated (rhizomes severed), shaded plants exhibited a greater decline in soluble carbohydrates than did shaded plants that retained viable rhizome connections to unshaded plants. Similar results have also been reported for Thalassia testudinum (Tomasko \& Dawes 1989).

The degree of clonal integration observed in $S y-$ ringodium filiforme falls within the range of patterns observed for other seagrass species. In Zostera noltii, a relatively small and fast growing seagrass, no significant differences were observed in apical growth or survival of clonal fragments comprised of 2, 5, or more ramets, indicating that RAM growth is not dependent on long-distance translocation of resources (Cabaço et al. 2005). In contrast, Thalassia testudinum exhibits a high degree of clonal integration with the survival and growth of small clonal fragments significantly lower than those of larger fragments (Tomasko \& Dawes 1989). In their studies of Cymodocea nodosa-a species similar to $S$. filiforme in size and growth form Terrados et al. (1997b) did not detect any significant reduction in RAM growth as a result of cropping up to 8 shoots from $C$. nodosa runners. This would indicate that C. nodosa RAMs either rely on translocation of resources over a longer distance than do those of $S$. filiforme (which showed reduced growth potential if 3 ramets were cropped from a runner) or are more capable of supporting growth by extracting resources stored in the rhizome. Therefore, while there is evidence of long-distance transport of resources in $\mathrm{S}$. filiforme, apical growth appears to be more dependent on resources translocated from ramets close to the meristem. In comparison, RAMs of C. nodosa are more dependent on resources translocated from distant ramets.

The fact that apical dominance is observed in $S y-$ ringodium filiforme and that apical growth is dependent on translocation of resources from older ramets indicates that clonal integration is an important factor affecting the growth form and productivity of this species. 
Acknowledgements. This work was funded by a fellowship from the George Barley Scholars Program with additional support from the Jones Environmental Research Fund administered through the University of Virginia, Department of Environmental Sciences. Logistical field support was provided by the Everglades National Park, Key Largo Office and the Keys Marine Lab. Significant field assistance was provided by E. Bricker, T. Frankovich, L. Reynolds and B. Wolfe. The authors also thank W. J. Kenworthy for detailed and constructive comments during the preparation of the manuscript.

\section{LITERATURE CITED}

Cabaço S, Alexandre A, Santos R (2005) Population-level effects of clam harvesting on the seagrass Zostera noltii. Mar Ecol Prog Ser 298:123-129

Callaghan TV, Jonasson S, Brooker RW (1997) Arctic clonal plants and global change. In: De Kroon H, Van Groenendael J (eds) The ecology and evolution of clonal plants. Backhuys Publishers, Leiden

Cline MG (1991) Apical Dominance. Bot Rev 57:318-358

Dawes CJ (1981) Marine Botany, 1st edn. Wiley-Interscience, New York

$>$ De Kroon H, Schieving F (1991) Resource allocation patterns as a function of clonal morphology: a general model applied to a foraging clonal plant. J Ecol 79:519-530

Duarte CM, Sand-Jensen K (1996) Nutrient constraints on establishment from seed and on vegetative expansion of the Mediterranean seagrass Cymodocea nodosa. Aquat Bot 54:279-286

Fonseca MS, Fisher JS (1986) A comparison of canopy friction and sediment movement between four species of seagrass with reference to their ecology and restoration. Mar Ecol Prog Ser 29:15-22

Fonseca MS, Fisher JS, Zieman JC, Thayer GW (1982) Influence of the seagrass, Zostera marina L., on current flow. Estuar Coast Shelf Sci 15:351-364

Fonseca MS, Kenworthy WJ, Thayer GW (1998) Guidelines for the conservation and restoration of seagrass in the United States and adjacent waters. NOAA COP/Decision Analysis Series 12

Grime JP (1994) The role of plasticity in exploiting environmental heterogeneity. In: Martyn ED, Caldwell N, Pearcy RW (eds) Exploitation of environmental hetergeneity by plants: Ecophysiological processes above- and belowground. Academic Press, San Diego, CA

Hemminga MA, Duarte CM (2000) Seagrass ecology. Cambridge University Press, Cambridge

Kenworthy WJ, Fonseca M, Whitfield PE, Hammerstrom KK (2002) Analysis of seagrass recovery in experimental excavations and propeller-scar disturbances in the Florida Keys National Marine Sanctuary. J Coast Res 37:75-85

Lefebvre LW, Reid JP, Kenworthy WJ, Powell JA (2000) Characterizing manatee habitat use and seagrass grazing in Florida and Puerto Rico: implications for conservation and management. Pac Conserv Biol 5:289-298

Libes M, Boudouresque CF (1987) Uptake and long-distance transport of carbon in the marine phanerogram Posidonia oceanica. Mar Ecol Prog Ser 38:177-186

Little RJ, Jones CE (1980) A dictionary of botany. Van Nostrand Reinhold Company, New York

Lovett Doust L (1981) Population dynamics and local specialization in a clonal perennial (Ranunculus repens). I. The dynamics of ramets in contrasting habitats. J Ecol 69: $743-755$

Lovett Doust L (1987) Population dynamics and local specialization in a clonal perennial (Ranunculus repens) III. Responses to light and nutrient supply. J Ecol 75:555-568

Marbà N, Duarte CM (1998) Rhizome elongation and seagrass clonal growth. Mar Ecol Prog Ser 174:269-280

Marbà N, Duarte CM (2003) Scaling of ramet size and spacing in seagrasses: implications for stand development. Aquat Bot 77:87-98

Marbà N, Hemminga MA, Mateo MA, Duarte CM, Mass YEM, Terrados J, Garcia E (2002) Carbon and nitrogen translocation between seagrass ramets. Mar Ecol Prog Ser 226:287-300

Rey JR, Stephens FC (1996) Effects of shading and rhizome isolation on soluble carbohydrate levels in blades and rhizomes of the seagrass Syringodium filiforme. Gulf Mex Sci $2: 47-54$

Salisbury FB, Ross CW (1992) Plant physiology, 4th edn. Wadsorth Publishing Company, Belmont

Sargent FJ, Leary TJ, Crewz DW, Kruer CR (1995) Scarring of Florida's seagrasses: assessment and management options. FMRI Tech Rep TR-1, Florida Marine Research Institute, St. Petersburg

Schwarzschild AC (2004) Leaf dynamics, clonal integratin and whole plant growth patterns of the seagrass Syringodium filiforme in the Florida Keys, Florida. PhD thesis, University of Virginia, Charlottesville

Terrados J, Duarte CM, Kenworthy WJ (1997a) Experimental evidence for apical dominance in the seagrass Cymodocea nodosa. Mar Ecol Prog Ser 148:263-268

Terrados J, Duarte CM, Kenworthy WJ (1997b) Is the apical growth of Cymodocea nodosa dependant on clonal integration? Mar Ecol Prog Ser 158:103-110

Tomasko DA, Dawes CJ (1989) Evidence for physiological integration between shaded and unshaded short shoots of Thalassia testudinum. Mar Ecol Prog Ser 54:299-305

Tomasko DA, Dawes CJ, Hall MO (1991) Effects of the number of short shoots and presence of the rhizome RAM on the survival and growth of transplanted seagrass Thalassia testudinum. Contrib Mar Sci 32:41-48

Tomlinson PB (1974) Vegetative morphology and meristem dependence: the foundation of productivity in seagrasses. Aquaculture 4:107-130

van der Hoeven EC, During HJ (1997) Positive and negative interactions in bryophyte populations. In: De Kroon $\mathrm{H}$, Van Groenendael J (eds) The ecology and evolution of clonal plants. Backhuys Publishers, Leiden

van Tussenbroek BI, Galindo CA, Marquez J (2000) Dormancy and foliar density regulation in Thalassia testudinum. Aquat Bot 68:281-295

Watson MA, Hay MJM, Newton PCD (1997) Developmental phenology and the timing of determination of shoot bud fates: ways in which the developmental program modulates fitness in clonal plants. De Kroon H, Van Groenendael J (eds) The ecology and evolution of clonal plants. Backhuys Publishers, Leiden

Williams SL (1987) Competition between the seagrasses Thalassia testudinum and Syringodium filiforme in a Caribbean lagoon. Mar Ecol Prog Ser 35:91-98

Zieman JC (1982) The ecology of seagrasses of south Florida: a community profile. FWS/QBS-82/25, US Fish and Wildlife Services, Office of Biological Services, Washington, DC

Submitted: April 7, 2007; Accepted: January 7, 2008

Proofs received from author(s): May 14, 2008 